\title{
Editorial \\ Revista Avaliação Psicológica - Número temático
}

\author{
DOI: http://dx.doi.org/10.15689/ap.2019.1804.ed
}

Com muita satisfação, apresenta-se o número temático da Revista Avaliação Psicológica que versa sobre a Psicologia Positiva. Identificar os pesquisadores que poderiam contribuir não foi difícil, pois eles se destacam nas pesquisas realizadas e na divulgação científica, assim como são membros de grupos de trabalho da Associação Nacional de Pesquisa e Pós-graduação em Psicologia (ANPEPP) ou mesmo de associações científicas, como a Associação Brasileira de Psicologia Positiva $(\mathrm{ABP}+)$. Em relação à última, compõe sua missão a ampliação da área, por meio da troca de informações.

Tem-se registro de que pesquisas desbravadoras sobre a 'Psicologia Positiva' ocorreram no Brasil no final de década de 1990, que estavam vinculadas a Programas de Pós-Graduação Stricto Sensu em Psicologia. Embora inicialmente em pequeno número, os estudos revelaram o pioneirismo do país, de modo que pode servir de referência para outros países nos quais a área é subdesenvolvida, como os da América do Sul. Destaque deve ser dado aos trabalhos realizados na Universidade Federal do Rio Grande do Sul, cujos pesquisadores foram responsáveis pela formação de muitos profissionais e, em consequência, pela nucleação da área. No presente número, por exemplo, são encontrados autores das regiões nordeste, centro-oeste, sudeste e sul do país.

Parte importante do avanço da área se deveu à publicação de instrumentos de avaliação psicológica, razão pela qual a publicação do número temático se justifica no presente periódico. Vários pesquisadores brasileiros da Psicologia Positiva têm a formação em avaliação psicológica e, em razão disso, transitam com maestria pela construção, adaptação e busca de evidências de validade de instrumentos. Hutz (2014) publicou importante livro, com o intuito de divulgar instrumentos de avaliação psicológica. A esse respeito, uma consideração deve ser feita. As medidas divulgadas nessa obra, e em outras têm sido utilizadas como recursos auxiliares em processos de avaliação, pois exclusivamente delas não dependem diagnósticos diferenciais ou de naturezas distintas. Assim, a escala de gratidão (Siqueira \& Freitas, 2019), do otimismo (Bastianello, Pacico, \& Hutz, 2014) e da compaixão (Marchetti, et. al, 2018) podem funcionar como importantes marcadores relacionados à saúde e que, se reunidos com outras informações, permitirão diagnósticos apurados sobre o funcionamento psicológico.

Ainda no que respeita o desenvolvimento da área, em recente publicação, Reppold, et. al (2019) afirmam que as principais aplicações, por meio de artigos e livros, dos pressupostos da Psicologia Positiva na área da saúde, no campo clínico, nas organizações e na área educacional já estão em português. A presente edição também reúne temáticas variadas. Nesse sentido, o leitor encontrará artigos sobre felicidade e flow, engajamento, bem-estar e satisfação de vida no trabalho. Por sua vez, o contexto educacional está contemplado pelo estudo da motivação e satisfação de vida, além de projeto de vida de adolescentes. As altas habilidades e a excelência são pesquisadas, assim como instrumentos de gratidão e de autocontrole.

Por fim, acredita-se que o número contribuirá para o avanço e aprimoramento da Psicologia Positiva. Espera-se que o leitor aproveite. Deseja-se boa leitura a todos.

Ana Paula Porto Noronha Editora Associada

\section{Referências}

Bastianello, M. R., Pacico, J.C., \& Hutz, C. S. (2014). Optimism, self-esteem and personality: Adaptation and validation of the Brazilian Version of the Revised Life Orientation Test (LOT-R). Psico-USF, 19(3), 523-531. doi:10.1590/1413-827120140190030

Hutz, C. S. (2014). Avaliação em Psicologia Positiva. Porto Alegre: ArtMed. 
Marchetti, E., Bertolino, C. O., Schiavon, C. C., Gurgel, L. G., Kato, S. K., Menezes, C. B., \& Reppold, C. T. (2018). Escala Breve de Compaixão Santa Clara: Propriedades Psicométricas para o Contexto Brasileiro. Avaliação Psicológica, 17(3), 371-377. doi: 10.15689/ ap.2018.1703.15208.10

Reppold, C. T., L. S. D’ Azevedo, Tocchetto, B. S., Diaz, G. B., Kato, S. K., \& Hutz, C. S. (2019). Avanços da Psicologia Positiva no Brasil. Revista Psicologia para América Latina, 32, 1-10.

Siqueira, F. Q., Freitas, L. B. L. (2019). Gratidão a benfeitores e reflexões sobre educação moral. Cadernos de Educação, 18, 89-110. 